\title{
Application and Exploration of Blending Learning in Course of Sales and Negotiating
}

\author{
Chongmei Wang \\ Shandong Institute of Business and Technology, Yantai, China \\ Worshipmei7654@163.com
}

Keywords: Blending learning, Teaching model, Sales and negotiating

\begin{abstract}
The development of Internet technology has changed classroom instructions pattern. It has supported advantages. Under the New Era Background, Blending learning, is a new model that consists of traditional teaching and E-learning, is used by some education comprises. Blending learning not only plays a dominant function that helps teachers to inspire, lead and control but also develops students' initiative and creativeness, combining traditional teaching of face-to-face with modern multimedia teaching to acquire a scientific effect of teaching. The article based on the course of Sales and Negotiating studies uses Blending Teaching well in teaching process to devote experience for teaching innovation.
\end{abstract}

Harold Bloom, a famous educator, said "a student was not a container you have to fill but you had to light up", who hoped the students would create their own learning initiative. Focusing on the teaching design includes knowledge' fragmentation and systematization, its theory using SPOC to motivate students' positivity and initiative .And his evaluation system turns Results-Orientation into Process -Orientation.

\section{Students Condition Analysis}

Traditional mode of teaching needs students to follow teachers' rules, being similar to a process that students acquire basic knowledge and skills such as concepts, theories and principles. And because of teachers' guidance, students can get a great deal of knowledge more quickly, centrally and systematically to develop well. In the whole process, As the subject of teaching activities, teachers are knowledge transmitters and students are just receivers. The teaching objective is to meet course' requirements. Although it has too many drawbacks, the traditional model of teaching can systematically and totally teach the cultural and scientific knowledge of human society for thousands of years. And the traditional model of teaching also has another disadvantage that teaching is simple and bored.Which causes students' negativity and prevents their emotional life in course, and teaching will become oppressive. And it will restrict students to develop. Thus, network and multimedia supply abundant instructional resources diversing paths of knowledge and the styles of teacher-student interaction, which is an efficient teaching model in teaching reforms, so as to create various learning styles ,convenient and diverse learning ways and profound learning experience and to develop teachers' dominant function and students' participatory function efficiently. And the teachers provide instructional video ,as the main form of learning resources, requiring students to finish viewing and learning in teaching resources before next class.This a new teaching model that comprises many activities such as completing homework questions, exploring subject questions, communicating experiences together and so on.

\section{Characteristic and Position of "Sales and Negotiating"}

\subsection{Talent training plan in "Sales and Negotiating"}

Sales and negotiating activity, a phenomenon of anytime and anywhere, which is not only an 
essential role that consists of interpersonal communications and interchangeable activities but a practical activity that requires students to face in social economic life ,which is essential in future business activity. The course of Sales and Negotiating, being an applied science that is based on psychology ,logic, communication, public relation and modern management theory, is a compulsory subject to train many kinds of talent for marketing and managing business .Based on the study students can know about fundamental features and law of sales and negotiation systematically to get its basic theories, methods and tactics to develop their qualities, skills and capacities.

\subsection{Teaching objectives and tasks}

The tasks of the course that base on Marketing and Management background aim at diversity problems in the Marketing and Management process to sale and negotiate so that companies can carry out Marketing activities well to increase revenue. The teaching objectives require students to get Sales and Negotiating fundamental theories and skills thoroughly so that students develop business of Sales and Negotiating by combining with actual practice. Therefore, students need to acquire basic knowledge of marketing and psychology, especially in competition awareness and creative thinking, so as to become excellent personals that undergo rigorous training to adapt business environment of modern companies of Sales and Negotiating after graduating.

\subsection{Characteristics of the course}

Being a strong practical course in Marketing, the course of Sales and Negotiating that requires active participation in discussions and diligent in thinking and practices to develop students' actual operation ability, attaches great importance to inducing-mode teaching and experiential learning .So by reform and innovation in teaching philosophy and methods, the course of Sales and Negotiating must be keep the course features and it should adapt applied talent' requirements of employing unit. So far, "Sales and Negotiating" pays more attention to theories rather than experiential teaching in teaching process. Or they just emphasize Case Study, lacking of imitating and experiencing part. Therefore, Blending Learning in course that is a breakthrough in traditional teaching compensates for cognate course' deficiency and highlights teaching process.

As a teaching innovation' attempt, the course of Sales and Negotiating pays more attention to applying theories, improving students' initiative and developing students' inner derivation and teachers' outer derivation, which are dual subject function. The study of teaching model is good for improving construction level of Marketing course and creating well environment of learning. And it avoids traditional and vacuous learning of theory that divorces from practice impelling students to learn expertise flexibly on the scene and develops student team awareness and comprehensive quantities that are available to companies. Blending learning provides a kind of modern flip-class teaching, which is helpful to the students to make full use of the debris time, adapted to the teaching needs and accepted by students, for Sales and Negotiating to improve the construction level of marketing's speciality, transport the highly skilled and to apply talents to the society.

\section{Thought of Blending learning}

Reversing the concept and process of traditional teaching, flip-class emphasizes knowledge that was imparted outside and absorbed in recess. Because of flip-class, the students' learning activities and teachers' teaching activities of sequence and combination will have different changes that the students become the main character of the class and the classroom activities are mainly based on the student's question inquiry or the topic report, the study achievement sharing, the discussion exchange and the question through a supplement that the knowledge is absorbed or revised,while teachers become the Learning activities Guide, mentor and interlocutor. So in order to achieve the goal of flip-class, Blending Learning requires teachers to know their design ideas clearly. 


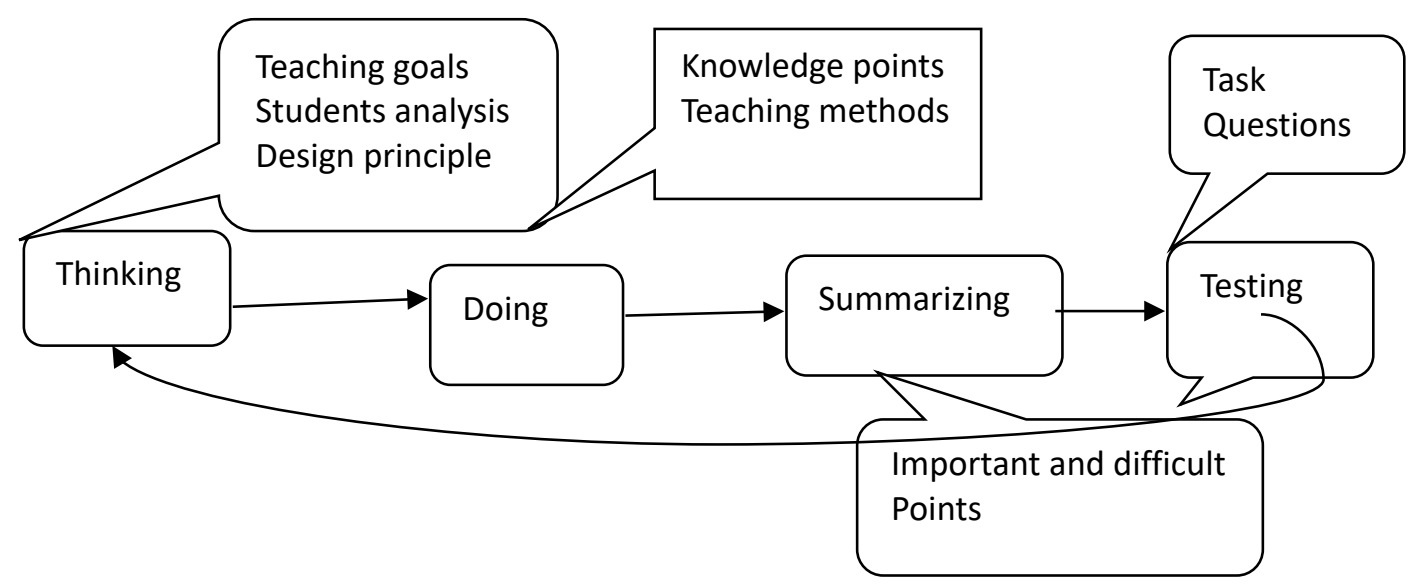

Figure 1 Blending teaching map

\section{The method and criteria of assessment}

Blending learning based on theory of flip-class teaching, emphasizing not only teachers' knowledge points in class but also autonomous and cooperative learning, getting from wonderful resource, paid more attention to developing students' information literacy and expression abilities because of blending learning, students' cognitive model and learning methods and teachers' teaching model and role change deeply. Therefore, course's assessment should lay stress on using multiplex evaluation system, combining with formative evaluation and summative evaluation and expanding the proportion of formative evaluation in addition. Formative evaluation comprises students' attendance, daily assignments, individual and group' learning quality and learning effectiveness, achievements exhibition, discussion activation and so on, which requires teachers to record well. Summative evaluation always test the overall consequence of students' learning to confirm that whether students reach the standard of the requirement of teaching objectives. Because the knowledge in teaching design is shared on the Internet, online data of learning behavior on the Internet is regarded as assessment criteria of students. However, if all students' learning engagement that includes video, discussion, topic that is opened, and online task, is regarded as course assessment, students maybe prefer to cheat and students prefer to watch TV and play games together or watch more videos and do more teats, through others ways that are non-effective for students, if videos make up a high proportion of course assessment, so that teachers should combine real tests with online learning when teachers design course assessment. Otherwise, teaching effect is difficult to guarantee. "Sales and negotiating" used the whole process of assessment that includes meeting class $(40 \%)$, online learning $(30 \%)$, and task(30\%).Among them, the meeting class implement the responsibility system of group leader, which has evaluation form and specific rules. At the end of each class, group leader will give members scores according to the rules. And teachers will carry out spot checks to inspect every group leader' implementation. According to Group leaders' assessment rules and final report, teachers will give them usual scores. Group assignment mainly assesses practical abilities of methods and strategies, the attitude of learning and the spirit of teamwork in process of simulation sales, which comes into being a central solution of assessment that is based on evaluating the abilities of cooperation and sales promotion, to motivate students to develop skills well and emphasize teamwork so that they can improve students' abilities that contain interpersonal communication ,flexible response and cooperation.

\section{References}

[1] DR Garrison,ND Vaughan. THE HANDBOOK OF BLENDED LEARNING: Global Perspectives, Local Designs[J]. Turkish Online Journal of Distance Education.2009,10(4):181-181. 
[2] CR Graham. Blended learning systems: Definition, current trends, and future directions[J]. International Conference on Hybrid Learning.2006.

[3] H Kashefi, Z Ismail, YM Yusof .Supporting Engineering Students' Thinking and Creative Problem Solving through Blended Learning[C]. Procedia - Social and Behavioral Sciences 2012.

[4] Frederick A.Russell,Frank H. Beach,Richard H.Buskirk,Selling:Principles and Practices, NY: McGraw-Hill Publishing Company,1998.

[5] David L.Kurtz,H.Robert Dodge,Jay E. Klompamaker,Professional Selling, Plano, Texas: Business Publications,Inc.,1985. 